\title{
NOTAS SOBRE A ARQUITETURA PRINCIPIOLÓGICA HUMANISTA E SOCIAL DA CONSTITUIÇÃO DA REPÚBLICA DE 1988 E A CONCRETIZAÇÃO DOS DIREITOS FUNDAMENTAIS NO CONSTITUCIONALISMO CONTEMPORÂNEO: UMA ABORDAGEM SOB O PRISMA DOS DIREITOS INDIVIDUAIS E SOCIAIS TRABALHISTAS
}

\author{
NOTES ON THE HUMANIST AND SOCIAL PRINCIPLES OF \\ BRAZIL'S CONSTITUTION OF 1988 AND THE IMPLEMENTATION \\ OF FUNDAMENTAL RIGHTS IN CONTEMPORARY \\ CONSTITUTIONALISM: AN ANALYSIS FROM THE PERSPECTIVE \\ OF INDIVIDUAL AND SOCIAL LABOR RIGHTS
}

\author{
Mauricio Godinho Delgado \\ Rúbia Zanotelli de Alvarenga \\ Tâmara Matias Guimarães
}

\section{RESUMO}

A evolução dos modelos de Estado foi marcada por fortes mudanças na relação existente entre Estado e sociedade. A constitucionalização de direitos de liberdade, a partir da criação do Estado de Direito, bem como a inovação na organização política, com a delimitação do poder estatal, marcaram o primeiro paradigma do constitucionalismo, deflagrado na Grã Bretanha na segunda metade do século XVII e, tempos depois, nos EUA e França, no final do século XVIII, representando, até hoje, relevância na ordem constitucional. Todavia, questões histórico-políticas demonstraram a necessidade de se erigirem direitos sociais, os quais, por fim, deflagraram o marco do segundo paradigma do constitucionalismo - o Estado Social, a contar das Constituições da segunda década do século XX, do México (1917) e da Alemanha (1919). O Estado Democrático de Direito, por sua vez - terceiro paradigma do constitucionalismo, inaugurado pelas Constituições da Europa Ocidental aprovadas depois da Segunda Grande Guerra (França, Itália, Alemanha, Portugal e Espanha, especialmente) e incorporado pela Constituição do Brasil de 1988 -, manteve os avanços alcançados 
até então, com o diferencial de conferir normatividade aos princípios. Assim, verifica-se a importância dos princípios jurídicos na construção dos direitos fundamentais, bem como a importância dessa categoria de direitos individuais e sociais na manutenção e aperfeiçoamento do Estado Democrático de Direito. A concretização dos direitos fundamentais encontra diversos obstáculos que devem ser analisados a fim de se encontrarem soluções aptas a possibilitar a concretização do princípio da máxima efetividade das normas constitucionais e do mínimo existencial por meio da ponderação de princípios.

Palavras-chave: Paradigmas do Constitucionalismo Ocidental. Estado Democrático de Direito. Democracia. Princípios. Direitos Individuais. Direitos Sociais. Concretização. Ponderação.

\section{ABSTRACT}

The evolution of state models was marked by strong changes in the relationship between state and society. The constitutionalisation of rights of liberty, with the creation of the rule of law, as well as the innovation in political organization, with the delimitation of state power, highlighted the first paradigm of constitutionalism, set off in Great Britain in the second half of the XVII century, later, in the USA and France, at the end of the XVIII century, representing, until today, relevance in the constitutional order. However, historical-political issues have demonstrated the need to establish social rights, which, in the end, set the stage for the second paradigm of constitutionalism - the Social State, from the Constitutions of the second decade of the XX century, Mexico (1917) and Germany (1919). The Democratic State of Law, in turn - the third paradigm of constitutionalism, inaugurated by the Constitutions of Western Europe adopted after the Second World War (France, Italy, Germany, Portugal and Spain, especially) and incorporated by the 1988 Brazilian Constitution - maintained the progress achieved so far, with the differential of giving normativity to the principles. The importance of legal principles in the construction of fundamental rights is verified, as well as the importance of this category of individual and social rights in the maintenance and improvement of the Democratic State of Law. The realization of fundamental rights has to face several obstacles that must be analyzed in order to find solutions capable of making possible the realization of the principle of maximum effectiveness of constitutional norms and the existential minimum through the weighting of principles. 
Keywords: Paradigms of Western Constitutionalism. Democratic state. Democracy. Principles. Individual Rights. Social rights. Implementation. Weighting.

\section{INTRODUÇÃO}

A evolução dos paradigmas do constitucionalismo, a partir das construções criadas pelos modelos de Estado Liberal de Direito e de Estado Social de Direito, foi muito importante na concepção da estrutura constitucional existente na atualidade. Todas as modificações atinentes aos direitos constitucionalmente protegidos e à relação existente entre Estado e sociedade foram necessárias para que houvesse um aperfeiçoamento da Constituição, possibilitando a criação do Estado Democrático de Direito. A formação de bases constitucionais adequadas, 0 refinamento dos bens jurídicos a serem protegidos, bem como a alteração na forma de aplicação das normas foram fundamentais nesse processo.

Nessa esteira, objetiva-se no presente estudo realizar uma análise acerca da referida evolução, destacando os aspectos essenciais de cada modelo do Constitucionalismo Ocidental. Ademais, a par das peculiaridades do paradigma do Estado Democrático de Direito, fazse essencial realizar um estudo sobre a normatividade conferida aos princípios, bem como os pilares humanísticos e sociais fundantes da Democracia.

Para tanto, a metodologia utilizada foi, quanto aos objetivos acima mencionados, a pesquisa descritiva. Quanto aos procedimentos técnicos, utilizou-se, especialmente, a pesquisa bibliográfica feita a partir de obras acadêmicas e artigos publicados em revistas especializadas no presente tema. Por fim, relativamente aos métodos de abordagem e de procedimento, aponta-se o método dedutivo, histórico e comparativo.

Além dos marcos essenciais do Constitucionalismo Ocidental, passase à análise detida acerca da importância dos princípios fundamentais, os quais tomam forma de direitos fundamentais, sejam eles individuais ou sociais, na construção do Estado Democrático de Direito. 
A normatividade conferida aos princípios foi primordial para garantir que, para além das regras constitucionais, também os valores e o espírito erigidos ao ápice pela Constituição tivessem força normativa equiparada às regras, ao invés de apenas caráter interpretativo e integrativo. Nesse sentido, o aperfeiçoamento dos direitos e garantias fundamentais, que trouxe os direitos sociais para o núcleo das constituições, também foi decisivo para se minimizar a exclusão dos segmentos populares, que estavam apartados das garantias instituídas constitucionalmente, até então.

Além disso, será abordado o problema da concretização dos direitos fundamentais que circundam, entre outros aspectos, a competência relativa à prestação desses direitos, a questão da alegada escassez de recursos, bem como a utilização da cláusula tida como implícita denominada "reserva do possível". No que se refere à limitação à efetividade dos direitos fundamentais, por meio da alegada restrição de recursos materiais (restrição econômica, principalmente, portanto), sugere-se a utilização da máxima da ponderação proposta por Alexy para a correta aplicação dos princípios fundamentais, em caso de conflito de normas.

Um recorte metodológico deve ser pontuado nesta "Introdução": em vista da imprescindível delimitação do objeto de qualquer pesquisa e reflexão científicas, buscou-se centrar, neste artigo acadêmico, a investigação e a análise efetivadas na dimensão social e humanista do Estado Democrático de Direito que abarque o campo jurídico sociotrabalhista, deixando-se, naturalmente, para outra pesquisa e análise - se for o caso - outras dimensões e aspectos da matriz humanista e social do constitucionalismo contemporâneo e, particularmente, da Constituição da República Federativa do Brasil. Porém compreende-se que o campo sociotrabalhista, por distintos fatores, expressa, com clareza e até ênfase, a arquitetura principiológica humanista e social do novo constitucionalismo e, inclusive, o necessário objetivo de concretização dos direitos fundamentais nesse constitucionalismo contemporâneo. ${ }^{1}$ 


\section{OS PARADIGMAS DO CONSTITUCIONALISMO OCIDENTAL: MARCOS ESSENCIAIS}

A compreensão da evolução do Constitucionalismo Ocidental tem lugar importante no estudo dos problemas ligados à concretização dos direitos individuais e sociais na atualidade. As mudanças históricas ocorridas ao longo dos últimos séculos foram relevantes para os contornos tomados pelo constitucionalismo, os quais foram marcados por lutas políticas e ideológicas.

Nesse sentido, assumindo a necessidade de entender como foram estabelecidos os valores fundamentais escolhidos pela sociedade, bem como a finalidade do Estado Democrático de Direito, tornase necessário estudar o caminho traçado pelos paradigmas do constitucionalismo ocidental, o que se fará aqui por meio de marcos históricos e políticos essenciais.

Conforme se sabe, o constitucionalismo contemporâneo amolda-se a contar das revoluções burguesas dos séculos XVII e XVIII, especialmente na Grã Bretanha, na França e nos EUA, dando origem a uma nova tradição jurídica que se desdobraria em três grandes padrões, a partir do constitucionalismo liberalista originário. De fato, após um longo ciclo criado pela Idade Moderna, onde a monarquia vigorou irrestrita, a burguesia se destacou entre o poder absoluto do rei e os percalços sofridos pelo povo. Os anseios por liberdade em face do período de opressão sofrido, na época, não poderiam mais ser restringidos por um suposto e ineficaz "Direito Natural” e, muito menos, por um ilegítimo direito divino dos monarcas.

A partir desses ideais libertários, fortalecidos nos séculos XVII e XVIII, a burguesia atentou-se para o fato de que a sociedade - e seus mais diversos contornos e problemas - não poderia ser simplificada ao ponto de apenas o Direito Natural regê-la. Seria necessário, portanto, pautar-se na limitação do poder estatal, bem como na participação mais ampla da sociedade na produção de regras pertinentes.

Vale destacar que, a partir das mencionadas revoluções - a saber, a Revolução Gloriosa Britânica do século XVII, a Revolução Francesa do século XVIII e a estruturação e independência dos EUA também do século 
XVIII -, é que se consolidou a vitória do liberalismo político, filosófico, cultural e jurídico (sem falar na consolidação da vitória acachapante do liberalismo econômico no mesmo período). Desde então, estrutura-se o primeiro paradigma do constitucionalismo, denominado de Estado Liberal de Direito ou paradigma do Constitucionalismo Liberal.

Desse modo, cabe destacar os direitos fundamentais protegidos por esse primeiro paradigma, quais sejam os direitos individuais relativos à vida, a diversas dimensões da liberdade individual (de locomoção; de expressão; de contratação; de reunião, etc.) e a diversas dimensões da propriedade privada (a própria propriedade privada; a livre iniciativa; a livre concorrência, etc.) (DELGADO, 2015, 2017; STRECK; DELGADO, 2014).

Verifica-se também que o constitucionalismo liberal, embora tenha se pautado em estabelecer limites ao poder estatal, não poderia ser visto como uma real democracia. 0 pensamento liberal não pregava a constitucionalização de direitos fundamentais de natureza e objetivos sociais, mas apenas direitos ligados ao individualismo, os quais beneficiavam quase que exclusivamente os segmentos proprietários, então capitaneados pela burguesia (BONAVIDES; MORAIS, 2004, 2014).

Os burgueses levantaram-se contra o Estado absolutista, defendendo o afastamento por completo do Estado das relações individuais e da vida privada a fim de criar direitos que garantissem o espaço do indivíduo, frisando que tais garantias eram materializadas apenas para uma pequena parcela da sociedade da época, composta, via de regra, por homens brancos e proprietários.

Esse primeiro paradigma do constitucionalismo também determina a separação dos poderes (BONAVIDES, 2004), para que o Estado tenha seus papéis muito bem definidos, sem ultrapassar esses limites e tampouco colocar-se acima da Constituição que passa a ser a norma maior. Nesse mesmo sentido, a separação dos poderes serviria como técnica importante de proteção aos direitos de liberdade. A teoria tripartite dos poderes, criada por Montesquieu, aduz que Executivo, Legislativo e Judiciários devem ser devidamente separados e limitados. Como bem apontam Lenio Luiz Streck e José Luiz Boszan de Morais, “[...] 
o liberalismo significou uma limitação da autoridade, bem como uma divisão da autoridade [...]" (STRECK; MORAIS, 2014).

A par disso, o liberalismo nasceu paralelamente ao surgimento e generalização do próprio positivismo jurídico. Segundo os critérios adotados por esse modelo jurídico, a formação de uma Constituição deveria ser compilada em um texto escrito, bem como inexistiria a inclusão de valores e princípios sociais de caráter normativo em seu bojo, uma vez que os burgueses necessitavam de plena segurança nas relações jurídicas criadas pelo liberalismo (BONAVIDES, 2004). ${ }^{2}$ Dessa feita, criou-se um cenário para que, ao lado de todos os direitos individuais instituídos, também fosse assegurada a permanência destes (ESPINDOLA; CUNHA, 2010).

Torna-se importante ressaltar que, embora existam referências a esse primeiro paradigma pelo epíteto de Estado Liberal-Democrático, entende-se que as premissas, valores e objetivos da democracia não se assemelham com o conteúdo filosófico, político e jurídico do liberalismo, dado que este não se volta à comunidade, mas ao indivíduo (BONAVIDES, 2004; DELGADO, 2017). Ora, o forte distanciamento e, até mesmo, a inegável tensão entre liberdade e igualdade nesse período, a larga sobreposição do fenômeno econômico sobre o fenômeno político, a par do largo império das relações privadas desiguais de poder, tudo demonstra a contradição de se intitular esse paradigma como democrático. Tratase de um paradigma liberal, sem dúvida; porém, dificilmente pode ser considerado, objetivamente, como democrático.

É necessário insistir que a ideia de liberdade propagada pelo liberalismo ostenta um significado muito restrito e, até mesmo, viezado. De um lado, ela se rege pelo império do individualismo, embora não tenha compreendido, ao longo de seu período hegemônico, que todos os indivíduos merecem ser igualmente favorecidos por ela; ao inverso, a ideia liberalista de liberdade conviveu, durante o período do Estado Liberal de Direito, com inúmeras e candentes modalidades de exclusão de indivíduos e grandes grupos sociais, tal como a escravidão nas Américas, a exclusão generalizada das mulheres na Europa e nas Américas, a exclusão ampla dos trabalhadores nos dois continentes, a par de outros tipos de exclusão (pessoas com deficiência, pobres em geral, etc.). De outro lado, 
essa peculiar ideia de liberdade propunha a abstenção do Estado e das políticas públicas em face dos principais mecanismos de poder existentes no interior do sistema econômico e do sistema social, esquecendo-se de que, com isso, ela sufragava, manifestamente, a exclusão de indivíduos e grupos sociais no âmbito da economia e da sociedade, em benefício de uma minoria socioeconômica.

Nesse quadro, a partir da segunda metade do século XIX, na Europa, e especialmente no século XX, esse ideário liberalista então hegemônico e seu Estado Liberal de Direito não conseguiram preservar as suas bases em equilíbrio, fazendo ganhar proeminência, desse modo, a necessidade e a busca de igualdade verdadeira, substantiva, real.

Nesse sentido, o grande trauma causado pelo liberalismo foram as tragédias criadas pela exploração desmedida da força de trabalho na Revolução Industrial, o que deixou claro que a plena liberdade contratual, a colocação da mão-de-obra humana como mera engrenagem do sistema, bem como a implantação de métodos desumanos de trabalho - pelo afã da produtividade - desencadearam situações de arbítrio pelos empregadores e pelo próprio Estado.

A partir de ideias igualitárias que remontam ao chamado "socialismo utópico", da primeira metade do século XIX, e, em seguida, ao "socialismo revolucionário", da segunda metade do século XIX em diante, articulase uma crítica cada vez mais contundente ao liberalismo originário. Tal crítica foi acompanhada também, mais à frente, ainda no século XIX, de vertentes do pensamento incrustadas nos próprios setores dominantes, como, ilustrativamente, o "socialismo de cátedra", o "humanismo cristão", o "trabalhismo", entres outras, as quais, em seu conjunto, apresentariam resultados mais efetivos apenas nas primeiras décadas do século XX.

Se não bastasse, formas novas de organização despontaram ao longo do século XIX, dirigindo-se ao combate à profunda desigualdade social propiciada pela emergência do capitalismo e pela hegemonia liberalista desde o período histórico iniciado no século anterior na Europa Ocidental. Organizações sindicais se estruturaram na Grã Bretanha e no continente europeu, dando origem, mais à frente, até mesmo a partidos políticos de extração trabalhista e popular, dinâmica que lançou cunhas 
importantes no sistema hegemônico deflagrado com as revoluções liberais precedentes.

Mais ao final do século XIX, percebeu-se o crescimento de concepções relativamente mais igualitárias inclusive entre segmentos dos próprios setores socialmente dominantes, de que são exemplos significativos a Conferência Internacional de Berlim, de 1890, a Encíclica Rerum Novarum, do Papa Leão XIII, de 1891, além da política trabalhista e previdenciária do governo Bismark implantada na recém unificada Alemanha. ${ }^{3}$

Todo esse contínuo processo de críticas e atenuações da desigualdade e exclusão socioeconômica características da era do Estado Liberal de Direito encontrou o seu ápice na conjuntura da Primeira Guerra Mundial, que abalou, profundamente, diversos países europeus. Nessa conjuntura, a propósito, ocorreu a Revolução Russa (1917), ponto máximo de denúncia, na História, das desigualdades da sociedade capitalista.

Em tal conjuntura, despontou a Constituição do México, de 1917, pioneira nas Américas quanto à inserção de regras jurídicas trabalhistas no interior do texto constitucional. Logo depois, surgiu a Constituição da Alemanha (Weimar, 1919), também capitaneando, na Europa, a nova fase de inserção de regras jurídicas trabalhistas no texto constitucional. Faz parte da mesma fase a criação da Organização Internacional do Trabalho, em 1919, pelo Tratado de Versalhes, a qual, em poucos anos, até 1930, iria aprovar cerca de 30 Convenções Internacionais do Trabalho e 30 Recomendações Internacionais.

Surge, então, o constitucionalismo social, que deflagra o segundo paradigma indicado, do Estado Social de Direito. Como visto, esse paradigma constitucional tem como marcos a Constituição Mexicana (1917) e a Constituição de Weimar da Alemanha (1919), sendo que, no Brasil, ele comparece por meio da Constituição de 1934, reafirmandose, mais à frente, por intermédio da Constituição de 1946 (STRECK; MORAIS, 2014).

Verifica-se, contudo, que o segundo paradigma do constitucionalismo consiste, essencialmente, em um modelo de transição em favor da democratização mais ampla da sociedade política e da sociedade civil ao invés de se tratar de um modelo complexo e sofisticado. Conforme indicam Lenio Streck e Bolzan de Morais, torna-se necessário reconhecer 
que, "mesmo sob o Estado Social de Direito, a questão da igualdade não obtém solução, embora sobrepuje a sua percepção puramente formal, sem base material" (STRECK; MORAIS, 2014, p. 98).

No Estado Social, de toda maneira, houve um significativo aprofundamento e ampliação do processo de constitucionalização dos direitos sociais, aqueles direitos humanos de segunda dimensão (ou de segunda espécie), quais sejam, os direitos sociais e coletivos vinculados ao mundo do trabalho (Direito do Trabalho) e da segurança e proteção estatais em face das carências humanas (Direito da Seguridade Social). A par disso, houve a redefinição do papel de outras dimensões de direitos fundamentais, como os direitos civis e, principalmente, os direitos políticos. É que estes passam a incorporar a noção de direitos individuais não mais restritos a titulares integrantes de pequenos - mas influentes grupos da sociedade, porém a todo o conjunto societário (ou, pelo menos, à grande maioria desse conjunto societário).

Vê-se, entretanto, como questão atinente ao Estado Social, a maior intervenção do Estado na vida das pessoas. Naturalmente, esse modelo supõe certa limitação das tradicionais liberdades individuais, para que o Estado se torne o responsável em suprir certas necessidades (BONAVIDES, 2004). Sem negar os benefícios deste modelo e seu avanço em face do paradigma anterior, verifica-se que ele, historicamente, concorreu para certa exacerbação do poder estatal, com o negligenciamento do tema democrático em algumas experiências históricas (daí se falar que ele não correspondia ainda a um modelo sofisticado, pronto, dotado de complexidade orgânica e bem estruturada).

Aliado a isso, outras restrições foram verificadas nesse segundo paradigma, uma vez que se vislumbrou celeuma quanto à limitação econômica para a implementação dos direitos sociais que foram constitucionalizados. Além disso, outro problema emerge do Estado Social de Direito, pois mesmo diante de uma aproximação do direito à moral, manteve-se o modelo positivista na disposição das normas constitucionais.

Nesse ínterim, verificou-se que o novo modelo proposto pelo Estado Social de Direito, no sentido da inclusão de direitos fundamentais de segunda geração no texto constitucional, trouxe grandes avanços e 
estes, indubitavelmente, devem ser mantidos. Contudo, um ponto em comum entre as Constituições criadas até então merece destaque: é que esse paradigma de constitucionalismo utilizava iguais fundamentos positivistas provindos do modelo antecedente, ambos negando a normatividade dos princípios.

Assim, em meados do século XX, logo depois da Segunda Grande Guerra, o Estado Social de Direito cedeu lugar, na Europa Ocidental, ao nascimento do terceiro paradigma do constitucionalismo, o Estado Democrático de Direito. 0 positivismo jurídico, que era mantido até então, deu lugar à concepção principiológica do Direito, conferindo normatividade aos princípios jurídicos - os quais, anteriormente, eram tidos apenas como pautas programáticas. Portanto, inicia-se um novo momento no constitucionalismo, dando espaço à criação de direitos fundamentais que fazem diálogo com a moral e a justiça.

\section{OS PILARES DO ESTADO DEMOCRÁTICO DE DIREITO NO CONSTITUCIONALISMO CONTEMPORÂNEO: A IMPORTÂNCIA DOS PRINCÍPIOS JURÍDICOS}

Os documentos constitucionais paradigmáticos desse novo constitucionalismo foram as Constituições da Europa Ocidental da segunda metade da década de 1940 - da França, da Itália e da Alemanha -, ao lado dos documentos constitucionais europeus da década de 1970, de Portugal e da Espanha. No Brasil, filia-se a essa novíssima tradição, a Constituição promulgada em cinco de outubro de 1988.

A Constituição de 1988, representando a materialização do Estado Democrático de Direito no Brasil, ao lado das Constituições europeias ocidentais mencionadas, todas trouxeram inovações relativas aos princípios no ordenamento jurídico de seus países (SARLET, 2002). Nesse contexto, previram título próprio para os princípios fundamentais, conferindo-lhes importância inusitada, prestando homenagem à sua nova função e significado.

Foi importante que a Constituição Brasileira tenha instituído princípios fundamentais basilares de toda a ordem constitucional, 
representando o núcleo indissolúvel do texto magno. Assim, a inclusão dos princípios jurídicos teve o condão de reconhecer outros direitos que o futuro, independentemente das condições e circunstâncias, pode exigir (ALEXY, 1993).

O Estado Democrático de Direito consagrou a normatividade dos princípios jurídicos. Além disso, estruturou significativa plêiade de princípios constitucionais, com destaque para os princípios humanistas e sociais do novo constitucionalismo. Nesse sentido, a propósito, pela primeira vez no Brasil, o princípio da dignidade da pessoa humana foi reconhecido como fundamento desse paradigma do Estado (art. 1으, III, Constituição Federal de 1988) (SARLET, 2002; DELGADO, 2015).

Importa se debruçar mais detidamente acerca desse aspecto inovador criado pelo Estado Democrático de Direito. Muito embora não seja um consenso entre todos os doutrinadores, o caráter normativo dos princípios é enfatizado por Jean Boulanger (França), Vezio Crisafulli e Norberto Bobbio (Itália), Joseph Esser e Robert Alexy (Alemanha), Federico de Castro, Luís Díez-Picazo e Joaquín Arce y Flores (Espanha), José Joaquim Gomes Canotilho (Portugal) e Ronald Dworkin (EUA), os quais contribuem para o progresso da Nova Hermenêutica e das recentes tendências axiológicas de compreensão do fenômeno constitucional (DELGADO, 2015). No Brasil, essa nova compreensão foi capitaneada, entre outros, pioneiramente, pelo constitucionalista Paulo Bonavides (DELGADO, 2015).

Com a construção das novas constituições ocidentais influenciadas pela renovação humanista e social da Europa Ocidental, os princípios passaram a conduzir o pensamento jurídico a uma concepção substancialista do Direito, ao invés de meramente formal, conforme abordado por Dicesar Beches Vieira Junior:

A busca por legitimação para as decisões principiológicas em sociedades complexas e plurais deu impulso ao desenvolvimento de diversas teorias da argumentação jurídica. Estas foram responsáveis por incorporar ao Direito metodologias e técnicas que o positivismo desprezava, como considerações de natureza moral, ou relacionadas à realidade subjacente as normas (VIEIRA JÚNIOR, 2014, p. 50). 
A normatividade dos princípios nas constituições contemporâneas lastreia a tendência que conduz à valoração e eficácia dos princípios como normas estruturantes de todo o sistema jurídico. Isso porque se afastou a natureza estritamente programática anteriormente brandida pela doutrina, mediante a qual se costumava neutralizar a eficácia das normas constitucionais. Nesse sentido, Mauricio Delgado e Gabriela Delgado assim explicitam:

Entre as inovações qualitativas essenciais do novo constitucionalismo encontram-se, ilustrativamente: a consagração da matriz principiológica das novas constituições; a institucionalização da natureza normativa dos princípios jurídicos; a estruturação de um rol de princípios humanísticos e sociais imperativos, todos apontando para a centralidade da pessoa humana na ordem social, econômica e jurídica; o aprofundamento e sofisticação dos mecanismos democráticos da sociedade política e da sociedade civil; a extensão da ideia de Democracia para além do simples campo do Estado e de suas instituições, de maneira a fazê-la presente também no âmbito das instituições da vida social e econômica privada (DELGADO; NEVES, 2017, p. 33).

0 reconhecimento da superioridade e hegemonia dos princípios na pirâmide normativa - bem como a supremacia que não é unicamente formal, mas, sobretudo, material - é possível na medida em que os princípios são compreendidos, equiparados e até mesmo confundidos com os valores essenciais da sociedade. Assim, na ordem constitucional dos ordenamentos jurídicos contemporâneos mais avançados, os princípios são a expressão maior da normatividade que fundamenta uma Constituição.

Convém frisar que os princípios contidos nessa nova ordem constitucional não traduzem apenas declaração ética, essencialmente moral, porém norma com caráter constitucional formal e material, realmente dotada de eficácia. Ademais, as regras também ostentam dimensão axiológica, conforme ensinado por Robert Alexy (ALEXY, 1993), mas, diferentemente dos princípios, contêm prescrições imperativas de conduta, onde se opera a lógica do tudo ou nada (all or nothing). Os princípios, por outro lado, são mandados de otimização (Alexy), contendo 
uma ordem que se deve realizar na medida do possível, considerando as possibilidades fáticas e jurídicas (ALEXY, 1993).

Com relação às funções dos princípios no ordenamento constitucional, é importante ressaltar que são inúmeras - a par de imediatas, a propósito, em decorrência da aplicabilidade imediata dos princípios jurídicos, particularmente os constitucionais. Inicialmente, destaca-se a função ordenadora dos princípios jurídicos. Ademais, os princípios ostentam função integradora e interpretativa, dando coerência geral ao sistema. Conforme indica José Afonso da Silva (SILVA, 2014), o fato de o Brasil constituir-se em um Estado Democrático de Direito, na matriz original de 1988, revela que a Constituição instituiu um novo tipo de Estado, não apenas no sentido formal, mas com objetivos concretos e claros, sem negar o seu sentido teleológico.

O Estado de Direito, como dito alhures, expressava um conceito eminentemente liberal, cujas premissas básicas eram a submissão ao império da lei, a divisão dos poderes e o enunciado e a garantia dos direitos individuais. Destaca-se, aliás, que esses postulados mantêm a sua importância até os dias correntes, como pressupostos do Estado de Direito. Como se sabe, o Estado de Direito evoluiu (e permanece em constante evolução), uma vez que o seu significado depende da própria ideia que se tem a partir do Direito.

O Estado Democrático de Direito, por outro lado, é qualificado não só pela participação efetiva do povo na coisa pública, mas também por realizar o princípio democrático como garantia geral dos direitos fundamentais. Como visto, nem o Estado Social de Direito conseguiu alcançar, na época, uma efetiva justiça social, embora tenha avançado nesse tema em comparação com o paradigma liberalista precedente. 0 Estado Democrático de Direito, portanto, surge como Estado fundante em uma perspectiva de realização social profunda pela ampliação e prática dos direitos sociais, bem como pela implementação dos instrumentos para a cidadania, possibilitando a concretização da justiça social, com base na dignidade da pessoa humana.

Nessa senda, Mauricio Godinho Delgado entende que o Estado Democrático de Direito pauta-se em um novo tripé conceitual composto pela "pessoa humana, com sua dignidade; sociedade política, concebida 
como democrática e inclusiva; sociedade civil, também concebida como democrática e inclusiva" (DELGADO, 2017, p. 45).

Assim, partindo da manutenção e fortalecimento dos três aspectos acima mencionados, o Estado Democrático de Direito caminha num processo de evolução que mantém os conceitos dos seus elementos componentes, mas permanece em constante evolução. Isso porque, nesse modelo de Estado, o poder será exercido democraticamente pelo povo, que apenas pode o fazer se encontrar no Direito as necessárias e adequadas garantias.

Portanto, resta evidente a importância que os princípios tomaram na construção do Estado Democrático de Direito. Embora parte da doutrina venha alertando acerca dos problemas que podem surgir dessa natureza e relevância conferida aos princípios - como, por exemplo, os estudos feitos por Luigi Ferrajoli, Lênio Streck e André Karam Trindade sobre o problema do subjetivismo interpretativo, do ativismo judicial e do denominado pan-principiologismo (FERRAJOLI; STRECK; TRINDADE, 2012) -, a verdade é que função que os princípios representam para a democracia ainda ostenta maior proeminência do que os problemas sugeridos. ${ }^{4}$

Ainda assim, cientes da relevância que os princípios têm - apesar das objeções à sua normatividade -, é importante exemplificar o destaque que ostentam na Constituição Federal de 1988, utilizando-se das lições de Ingo Sarlet (SARLET, 2002), as quais asseguram que os princípios fundamentais estão diretamente ligados aos direitos fundamentais constitucionalmente protegidos. Dessa maneira, o direito à vida, assim como os direitos à liberdade e à igualdade, todos estão vinculados à dignidade da pessoa humana (DELGADO, 2015. 


\section{OS PILARES DO ESTADO DEMOCRÁTICO DE DIREITO NO CONSTITUCIONALISMO CONTEMPORÂNEO: A IMPORTÂNCIA DOS DIREITOS INDIVIDUAIS E SOCIAIS FUNDAMENTAIS}

Os direitos individuais e sociais fundamentais são parte do núcleo das Constituições democráticas contemporâneas. Inicialmente, faz-se necessário deixar claro acerca de quais direitos fundamentais estamos tratando. Para tanto, adotar-se-á a metodologia utilizada por Ingo Wolfgang Sarlet (SARLET, 2004), dividindo os direitos fundamentais em primeira, segunda, terceira e quarta dimensões. Obviamente, os direitos fundamentais não assumiram, em um mesmo instante histórico, a forma e o conteúdo que apresentam atualmente. Pelo contrário, estruturaramse em uma evolução lenta e hesitante, a par de diferenciada segundo a experiência nacional vivida.

Os direitos fundamentais sofreram e continuam sofrendo diversas transformações no que diz respeito ao seu conteúdo, titularidade e efetividade. A partir das primeiras Constituições escritas, os direitos fundamentais nelas inseridos foram identificados como direitos eminentemente individualistas, de cunho negativo, que indicavam o afastamento do Estado do indivíduo, tais como, direito à vida, à liberdade, à defesa e à propriedade, que são os chamados de direitos de primeira dimensão (ou de primeira espécie).

Todavia, diante dos graves problemas despontados com o avanço do capitalismo - inicialmente despontado na indústria, mas se tornando logo a seguir, um sistema multidimensional -, notadamente sob a perspectiva social e econômica, passou a ficar cada vez mais claro que a mera garantia de direitos de igualdade e liberdade formais não representava garantia de efetividade dos mesmos (SARLET, 2004). Assim, no século XIX, começaram a surgir os direitos de dimensão positiva, que pressupunham grande participação do Estado na sociedade, o qual era o responsável por propiciar a participação do povo no Estado Social.

Consoante ensina Ricardo Luís Lorenzetti: 
A classificação dos direitos em função das gerações tem um sentido histórico, antes que normativo. Os primeiros direitos fundamentais referiam-se à liberdade, e foram consagrados a partir da Declaração dos Direitos do Homem - por isso são os da "primeira geração". A segunda categoria de direitos reconhecida foi a dos denominados "direitos sociais": direito ao trabalho, moradia digna, saúde. Foram incorporados através do constitucionalismo social, de meados do século XX (LORENZETTI, 2009, p. 104).

Nesse contexto, os direitos de segunda dimensão (ou geração ou espécie), quais sejam, saúde, educação, moradia, emprego, transporte massivo, cultura, entre outros, demandam, em grande medida (embora não exclusivamente - vide os direitos individuais e sociais trabalhistas), uma prestação positiva por parte do Estado, tendo o condão, primordialmente, de propiciar o alcance da igualdade material entre as pessoas. Esses direitos têm a finalidade de propiciar o bem-estar social para uma subsistência digna da população, independentemente de sua condição econômico-financeira, origem, etnia, gênero, religião.

A constitucionalização dos direitos sociais se deu, historicamente, a partir da primeira década do século XX, por intermédio de novos documentos constitucionais então surgidos, tais como a Constituição do México, de 1917, e a Constituição de Weimar, de 1919 (no Brasil, esse paradigma despontou na Constituição de 1934, reiterando-se na Constituição de 1946). Nessa fase, porém, os direitos tidos como sociais englobavam, essencialmente, os direitos individuais e sociais trabalhistas e os direitos individuais e sociais previdenciários.

Entretanto, somente com as inovações trazidas pelo subsequente Constitucionalismo Humanístico e Social, construído depois da Segunda Grande Guerra, na Europa Ocidental, por intermédio das Constituições da França (1946), Itália (1947), Alemanha (1949), Portugal (1976) e Espanha (1978), é que foi possível criar uma nova e abrangente matriz constitucional em que o ser humano e sua dignidade intrínseca se tornassem o ponto cardeal, além da ênfase no caráter inclusivo e democrático tanto da sociedade política como da sociedade civil, a par da inovadora normatividade dos princípios jurídicos (DELGADO, 2015, 2017).

A par disso, nesse novo paradigma constitucional, os direitos sociais se alargaram, englobando não apenas os direitos trabalhistas e 
previdenciários, como também os direitos à saúde, à educação, à moradia, ao transporte massivo de pessoas, à cultura, ao lazer, entre outros direitos. Não é por outra razão, inclusive, que o paradigma do Constitucionalismo Humanista e Social melhor se concretizou, na História, na experiência do Estado de Bem-Estar Social da Europa Ocidental, em que tal leque ampliado de direitos sociais foi efetivamente consagrado (STRECK, 2014; CANOTILHO, 2003).

No Brasil, em 1988, a Constituição Federal ganhou protagonismo, não só por incorporar, manifestamente, o paradigma do Constitucionalismo Humanista e Social, adotando o modelo do Estado Democrático de Direito, mas por enfatizar, pedagogicamente, alguns dos mais importantes pilares desse paradigma, tais como, a normatividade dos princípios jurídicos, um largo rol de princípios constitucionais humanistas e sociais, o destaque topográfico conferido em seu corpo à centralidade da pessoa humana e aos direitos individuais e sociais, inclusive os trabalhistas.

Nesse contexto, a Constituição de 1988, em seu Título II, tratou dos "Direitos e Garantias Fundamentais", apontando, no Capítulo II desse mesmo título, largo elenco de direitos sociais, quer trabalhistas, quer de outra espécie. Assim, o art. 6º, que integra o Capítulo II do Título II, enuncia os seguintes direitos sociais: "São direitos sociais a educação, a saúde, a alimentação, o trabalho, a moradia, o transporte, o lazer, a segurança, a previdência social, a proteção à maternidade e à infância, a assistência aos desamparados, na forma desta Constituição" (redação atualizada, após inseridas as mudanças feitas por emendas constitucionais subsequentes a 1988).

Ao lado desse preceito de caráter geral sobre os direitos individuais e sociais, desponta o art. $7^{0}$ da Constituição, abrangendo 34 incisos e parágrafo único. 0 dispositivo constitucional enuncia outros direitos sociais, especificamente de natureza trabalhista. Tal preceito, aliás, expõe diversos importantes princípios justrabalhistas (portanto, princípios constitucionais aplicáveis ao Direito do Trabalho), a par de vários direitos assegurados aos trabalhadores.

É preciso registrar, de todo modo, que embora se faça, para fins meramente didáticos, a distinção dos direitos fundamentais a partir de dimensões (ou, até mesmo, de espécies), o fato é que os direitos individuais, 
sociais e públicos atados à ideia básica de liberdade - que começaram a ser identificados na primeira fase do constitucionalismo ocidental -, a par dos direitos eminentemente sociais e, até mesmo, econômicos (que começaram a ser identificados na segunda fase do constitucionalismo, acentuando-se, por fim, na terceira e atual fase constitucionalista), eles se imbricam e se complementam entre si, sem a menor dúvida. Todos têm a natureza de direitos individuais fundamentais, ainda que alguns sejam, ao mesmo tempo (particularmente, os direitos denominados sociais, inclusive os trabalhistas), direitos individuais e sociais fundamentais.

Outra análise sobre os direitos fundamentais a eles se reporta também como princípios fundamentais. Ou seja, grande parte deles ostenta o caráter não apenas de direitos (isto é, vantagens reconhecidas pela ordem jurídica), mas igualmente como princípios jurídicos. Nessa linha, segundo Robert Alexy (ALEXY, 1993), as normas de direitos fundamentais são, não raras vezes, confundidas com os princípios. 0 mesmo autor pondera que os direitos fundamentais têm, essencialmente, o caráter normativo duplo, uma vez que estes carregam em si características de princípios e de regras.

Diante disso, destaca Luís Roberto Barroso:

Para poderem beneficiar-se do amplo instrumental do Direito, migrando da filosofia para o mundo jurídico, esses valores compartilhados por toda a comunidade, em dado momento e lugar, materializam-se em princípios, que passam a estar abrigados na Constituição, explícita ou implicitamente. Alguns nela já se inscreviam de longa data, como a liberdade e a igualdade, sem embargo da evolução de seus significados. Outros, conquanto clássicos, sofreram releituras e revelaram novas sutilezas, como a separação dos Poderes e o Estado democrático de direito. Houve, ainda, princípios que se incorporaram mais recentemente ou, ao menos, passaram a ter uma nova dimensão, como o da dignidade da pessoa humana, da razoabilidade, da solidariedade e da reserva de justiça (BARROSO, 2002, p. 2).

Vem à tona, portanto, a questão relativa à diferenciação entre regras e princípios, quanto ao modo de sua aplicação - tema exaustivamente enfrentado por notáveis constitucionalistas, como, por exemplo, Robert Alexy (1993) Ronald Dworkin (1999) e Paulo Bonavides (2000). Pontuese que as regras são aplicadas seguindo a lógica do tudo ou nada ao passo 
que os princípios são aplicáveis na medida do possível. Pontue-se também que, em caso de princípios colidentes, nem sempre um princípio elimina a aplicação de outro. Desse modo, se os direitos fundamentais podem estar consubstanciados em regras ou princípios, faz-se necessário analisar o suporte fático dos direitos fundamentais:

Embora normalmente sem referência à expressão "suporte fático" ou a alguma teoria sobre ele, é comum que se pergunte se esse ou aquele ato, fato ou estado é protegido por essa ou aquela norma que garante um direito fundamental, ou se essa ou aquela ação estatal configura, ou não, uma intervenção nesse âmbito de proteção. [...] Assim, as consequências do que se entende por suporte fático e, sobretudo, de sua extensão são enormes e de vital importância na teoria e na prática dos direitos fundamentais (SILVA, 2009, p. 68).

Essa análise é essencial para compreender o modo de aplicação do direito fundamental ao caso concreto. Não há dúvida que há maior previsibilidade quanto ao conteúdo das regras em comparação ao conteúdo dos princípios, como dito. Todavia, o modelo chamado misto, constituído de regras e princípios que constituem os direitos fundamentais é, segundo Robert Alexy (1993), o modelo que melhor atende à Teoria dos Direitos Fundamentais.

Dessa feita, os direitos fundamentais não estão limitados a um sistema fechado e restritivo. Ao inverso, integram-se a um sistema relativamente dinâmico, apto a viabilizar que os direitos fundamentais sejam moldados a partir da própria evolução da humanidade - evolução guiada pelo princípio basilar da dignidade da pessoa humana.

Assim, o Título II ("Dos Direitos e Garantias Fundamentais" - arts. 5 ao 17) da Constituição Federal de 1988 elenca uma série de regras e princípios que protegem constitucionalmente os direitos próprios da pessoa humana. Além disso, a Constituição, enfaticamente, também tratou de proteger tais direitos fundamentais de modificações tendentes a os abolir, por meio do art. $60, \S 4^{\circ}$, IV, incluindo-os como cláusula pétrea.

Com relação à eficácia dos direitos fundamentais, o próprio texto original de 1988 demarcou preceito claro nesse sentido: “Art. 5ㅇ. (...) $\S 1^{\circ}$ As normas definidoras dos direitos e garantias fundamentais têm aplicação 
imediata". Nesse quadro, prepondera na doutrina a compreensão concernente à eficácia imediata das normas definidoras dos direitos e garantias fundamentais. A esse respeito, leia-se, por exemplo, a afirmação destacada pelo jurista Luís Roberto Barroso, em obra de 2009:

Lembremos que não há, em uma Constituição, cláusula a que se deva atribuir meramente o valor moral de conselhos, avisos ou lições. Todas têm a força imperativa de regras, ditadas pela soberania nacional ou popular aos seus órgãos (BARROSO, 2009, p. 82).

É bem verdade que, na prática concreta da jurisprudência, despontam situações de relativização da eficácia imediata dos direitos fundamentais. Um exemplo nessa direção concerne à norma inserida no inciso I do art. $7^{0}$ da Constituição, que se refere à «relação de emprego protegida contra despedida arbitrária ou sem justa causa, nos termos de lei complementar, que preverá indenização compensatória, dentre outros direitos". Passados mais de 30 anos da vigência da Constituição, não sobreveio a lei complementar mencionada no inciso constitucional, nem interpretação jurisprudencial dominante no sentido de conferir qualquer mínima eficácia à norma protetora construída em cinco de outubro de 1988.

De toda maneira, apesar da relevância evidente que têm os direitos individuais e sociais fundamentais, a problemática envolvendo a efetividade de tais direitos, em especial, os direitos sociais, merece apreço e análise detida, em vista de alguns fatores que contribuem particularmente para a falha em sua concretização. Tais fatores serão abordados a seguir.

\section{A CONCRETIZAÇÃO DOS DIREITOS INDIVIDUAIS E SOCIAIS FUNDAMENTAIS NO ESTADO DEMOCRÁTICO DE DIREITO: PARÂMETROS RELEVANTES}

Inicialmente, destaca-se que a questão da concretização dos direitos fundamentais, sejam eles individuais ou sociais, circunda o fato de que o intérprete e operador do Direito tem de ter a consciência axiológica de quais valores foram levados em consideração na constitucionalização desses 
direitos. Dessa maneira, a efetivação de direitos fundamentais encontra-se não somente na seara do dever de cumprir o dispositivo constitucional, mas na própria consciência de que se trata de princípios, valores e regras reconhecidos como os mais importantes pela própria sociedade.

Nesse sentido, não há dúvida de que a violação de direitos fundamentais ou mesmo a sua não efetivação - já que eles ostentam aplicabilidade imediata (art. 5으, §1으, CF/88) - tudo implica na ofensa ao núcleo essencial do Constitucionalismo Humanista e Social e, claramente, da Constituição de 1988. Todavia, conforme já abordado, os direitos fundamentais não podem ser tomados de maneira isolada, ou seja, convivem ao mesmo tempo com outros direitos que podem lhes ensejar certa limitação e, não raro, apresentam determinado grau de subjetividade, circunstâncias que dificultam a sua concretização absoluta.

A análise do problema da implementação dos direitos fundamentais perpassa pela abordagem de quem são os responsáveis pela concretização desses direitos. A concretização dos direitos fundamentais exige uma relação entre Estado e sociedade (eficácia vertical dos direitos fundamentais) que envolve direitos de defesa (negativos) e direitos à prestação (positivos), (ALEXY, 1993).

Mas, conforme sabemos, tal concretização envolve também uma relação específica entre segmentos da própria sociedade (eficácia horizontal ou diagonal dos direitos fundamentais), dado que parte dos direitos individuais e sociais fundamentais, especialmente os trabalhistas, envolvem prestação positiva (ou omissão respeitosa) por entidades institucionais e empresariais privadas.

Nesse enfoque, alguns direitos fundamentais exigem uma ação maior e mais intervencionista do Estado do que outros. Tais ações relacionam atividades de todos os Poderes da República - Executivo, Legislativo e, até mesmo, do Poder Judiciário, neste caso, relativamente à qualidade e o direcionamento constitucionais de suas interpretações jurídicas. Evidentemente que todos esses poderes devem atuar no padrão constitucional, isto é, de forma independente e harmônica entre si; no caso do Poder Judiciário, contudo, seu compromisso institucional basilar é com a guarda da Constituição da República, ao invés do alinhamento 
com ideologias conjunturalmente dominantes em certo período histórico vivenciado pelo País.

Ao Poder Legislativo caberia a função de criar as leis que possibilitem a implementação dos direitos fundamentais; ao Poder Executivo, a concretização desses direitos em favor da sociedade, geralmente, por meio de políticas públicas; por fim, ao Judiciário, além do controle constitucional das leis criadas pelo Poder Legislativo, caberia também solucionar as controvérsias e aplicar a ordem jurídica aos casos concretos, sempre guardando a higidez e a efetividade da Constituição da República.

Todavia, é sabido que a despeito da aplicabilidade imediata dos direitos fundamentais, é impossível concretizar todos eles de maneira plena e, segundo parte da doutrina, ao menos o mínimo existencial deve ser garantido pelo Estado, tendo em vista que é de competência predominante deste a concretização dos direitos fundamentais. É bem verdade que essa noção de mínimo existencial passível de concretização efetiva, infelizmente, pode propiciar uma subjetiva e injustificável diminuição dos direitos fundamentais, por razões de ordem econômica e conjuntural, mediante o manejo de um suposto princípio jurídico brandido pela jurisprudência e pela doutrina - a cláusula implícita denominada de "reserva do possível". Ora, o manejo desproporcional e reiterado desse subprincípio (se se tratar, realmente, de um princípio constitucional, ressalve-se), entretanto, pode, na prática, descaracterizar a própria matriz civilizatória da Constituição da República.

Como observa J. J. Gomes Canotilho:

O entendimento dos direitos sociais, econômicos e culturais como direitos originários implica, como já foi salientado, uma mudança na função dos direitos fundamentais e põe com acuidade o problema da sua efetivação. Não obstante se falar aqui da efetivação dentro de uma - reserva possível -, para significar a dependência dos direitos econômicos, sociais e culturais não se reduz a um simples "apelo" ao legislador. Existe uma verdadeira imposição constitucional, legitimadora, entre outras coisas, de transformações econômicas e sociais na medida em que estas forem necessárias para a efetivação desses direitos (CANOTILHO, 2003, p. 474).

Neste ponto, será necessário retomar o debate acerca dos princípios fundamentais. Além das diferenças entre princípios e regras já expostas, 
é necessário destacar que, no que se refere ao conflito entre normas, mais uma vez, regras e princípios se distinguem. Nesse sentido, segundo a compreensão dominante, esteada em Robert Alexy, o conflito entre regras é solucionado seguindo a lógica de que sempre apenas uma só regra é válida para determinado contexto fático; todavia, havendo conflito entre princípios, é plenamente possível que, em face de um caso concreto, mais de um princípio fundamental seja aplicável (ALEXY, 1993).

Os princípios, como abordado anteriormente, consistem em espécie de normas jurídicas por meio das quais são estabelecidos comandos de otimização aplicáveis em vários graus, segundo as possibilidades normativas e fáticas. Portanto, assim como os direitos fundamentais também são concebidos como princípios, é necessário que, evidenciadose o conflito entre eles, seja feito o devido balanceamento de princípios (ponderação) para solucionar o caso difícil (ALEXY, 1993). Assim, o sopesamento de direitos que estejam em choque deve ser realizado considerando que quanto maior for a afronta ao direito fundamental, maior deve ser o peso aplicado ao princípio que lhe confere suporte embora sem negligência ao princípio contraposto.

A técnica da ponderação (ALEXY, 1993) é realizada sempre que, diante de um caso concreto, ocorra a colisão de princípios. Assim será verificado qual princípio prepondera em face do outro, embora seja importante frisar que o princípio sucumbente não perderá sua validade, nem eficácia. Registre-se que não há, abstratamente, a possibilidade de se estabelecer qual princípio deva prevalecer sobre o outro, pois isso se dará a partir da análise do caso concreto, avaliando as condições fáticas e jurídicas.

Nesse sentido, a máxima da proporcionalidade (expressão de Robert Alexy), (1993) é aplicável a partir da verificação dos seguintes pontos: adequação, necessidade e proporcionalidade em sentido estrito. Em tal quadro, a fórmula do sopesamento pode ser dividida em três passos: no primeiro, será avaliada a existência, ou não, de coerência entre o direito fundamental a ser limitado e a finalidade que a norma deseja alcançar; no segundo passo, avaliar-se-á, no caso concreto, se o meio escolhido foi o que representou menor sacrifício para o direito colidente; por fim, no terceiro passo, no tocante à proporcionalidade em sentido estrito, será 
buscada a solução mais adequada para o caso concreto, ou seja, a solução que venha ensejar mais benefícios do que malefícios.

Assim, caso se entenda que a natureza da "reserva do possível" seja de princípio ou, pelo menos, de subprincípio (o que, em si, é questionável, por se tratar de óbvio obstáculo à realização de princípios constitucionais), sua aplicação deve ser vista como uma cláusula de reserva que toma em ponderação o seguinte: se, no caso concreto, outro princípio não obtiver maior peso. Ou seja, para haver a correta análise de qual princípio será preponderante sobre outro, terá que ser aplicada a ponderação; caso contrário, ocorrerá uma reiterada e metajurídica vinculação do resultado interpretativo aos desígnios e interesses conjunturais estatais, em detrimento das prestações de direitos fundamentais. É o que aponta Gomes Canotilho:

Quais são, no fundo, os argumentos para reduzir os direitos sociais a uma garantia constitucional platônica? Em primeiro lugar, os custos dos direitos sociais. Os direitos de liberdade não custam, em geral, muito dinheiro, podendo ser garantidos a todos os cidadãos sem se sobrecarregarem os cofres públicos. Os direitos sociais, pelo contrário, pressupõem grandes disponibilidades financeiras por parte do Estado. Por isso, rapidamente se aderiu a construção dogmática da reserva do possível (Vorbehalt des Moglichen) para traduzir a ideia de que os direitos sociais só existem quando e enquanto existir dinheiro nos cofres públicos. Um direito social sob "reserva dos cofres cheios" equivale, na prática, a nenhuma vinculação jurídica (CANOTILHO, 2003, p. 477).

Aliás, deve ser notado que o manejo da peculiar "reserva do possível", na interpretação constitucional, pode ensejar, conforme visto, uma reiterada e metajurídica vinculação aos desígnios conjunturais do Estado como também aos próprios interesses privados econômica, social e ideologicamente dominantes - com o que se retorna, por vias transversas, ao estuário restritivo e excludente do liberalismo primitivo, mesmo em contexto histórico regido pelo Constitucionalismo Humanista e Social. ${ }^{5}$

É importante aquilatar, por fim, que a utilização da proporcionalidade serve como parâmetro para as ações dos Poderes Executivo, Legislativo e Judiciário, visto que, independentemente de eventual escassez de 
recursos, é necessário assegurar, ao menos, o mínimo existencial para que haja garantias mínimas de igualdade e de distribuição de direitos.

Dessa feita, a utilização racional dos recursos, a fim de concretizar direitos fundamentais, deve ser manejada dentro dos parâmetros da razoabilidade e proporcionalidade. Além disso, também é necessária transparência no que se refere à alocação de recursos, garantindo que a sua destinação siga a importância dada pela Constituição de 1988 aos direitos fundamentais.

\section{CONCLUSÃO}

A evolução do Constitucionalismo Ocidental trouxe avanços para o Direito, assim como melhorias à relação existente entre Estado e sociedade, a par da relação existente entre as forças e poderes enraizados no próprio interior dessa sociedade. A ideia de liberdade e igualdade meramente formais, brandida pelo Estado Liberal de Direito, foi agregada pelas ideias de liberdade e de igualdade substanciais - próprias às duas fases subsequentes do constitucionalismo. Estas concepções e fatos novos abriram largo espaço para a criação de direitos até então desconhecidos, a par de espaço real para a efetivação dos antigos e novos direitos. E essa efetivação aconteceu quer por intermédio da atuação estatal, quer pela garantia de maior equidade social no contexto interno da própria sociedade civil, isto é, no interior das relações sociais e econômicas.

O terceiro paradigma do constitucionalismo, do Estado Democrático de Direito (também denominado Estado de Direito Democrático ou Constitucionalismo Humanista e Social), deflagrado na Europa Ocidental logo depois do término da Segunda Grande Guerra, realizou-se, pelo menos nas sociedades políticas e civis situadas no centro e no norte europeus ocidentais, mediante a fórmula do Estado de Bem-Estar Social. Nessa fórmula altamente exitosa foram reunidas, no contexto de sistemas econômicos capitalistas (cada um com sua especificidade nacional), diversas prestações positivas estatais em favor da população no campo da saúde, da educação, do transporte massivo de pessoas, da moradia, da cultura, do lazer etc., ao lado dos direitos individuais e 
sociais trabalhistas assegurados por diplomas legais ou internacionais imperativos, senão garantidos pela negociação coletiva sindical perante as empresas e instituições empregadoras, no âmbito da sociedade civil.

0 atual paradigma do Estado Democrático de Direito, com o seu conteúdo e o seu direcionamento humanísticos e sociais, trouxe à tona a constitucionalização de direitos fundamentais individuais e sociais, potencializados mediante um diferencial de notável relevância, qual seja, a normatividade conferida aos princípios jurídicos. Assim, os princípios jurídicos que, anteriormente, eram utilizados apenas de maneira subsidiária, agora ostentam normatividade jurídica, podendo ocupar, inclusive, a forma de direitos fundamentais, tal como ocorre na Constituição da República Federativa do Brasil, de 1988.

Diante da importância conferida aos princípios, por meio do novo paradigma do constitucionalismo, é necessário ressalvar que, embora tenham baixa densidade normativa e acentuada subjetividade, os princípios jurídicos fundamentais (direitos fundamentais que tomam a forma de princípios) ostentam a mesma relevância que as regras constitucionais, tendo aplicabilidade imediata, objetivando necessariamente a sua concreta efetivação.

O presente estudo pautou-se na análise da referida evolução, bem como da realidade inarredável da existência de obstáculos à concretização dos direitos fundamentais. Assim, verifica-se que, no Brasil, a cláusula da "reserva do possível" (ou epítetos congêneres por ela assumidos na atualidade) tem sido utilizada pelo poder estatal e pela iniciativa privada para abrandar (ou conseguir abrandar) direitos fundamentais, em contextos conjunturais inóspitos.

Assim, propõe-se a utilização da técnica de ponderação criada por Robert Alexy, a fim de que o conflito entre princípios seja dirimido de maneira adequada e proporcional, afastando-se o manejo da cláusula da "reserva do possível" como fórmula conjuntural de frustração da efetividade dos direitos fundamentais. 


\section{NOTAS}

1 A arquitetura principiológica humanista e social da Constituição de 1988 e a concretização dos direitos fundamentais no constitucionalismo contemporâneo envolve, conforme se sabe, múltiplos aspectos e, por consequência, múltiplos campos do Direito. Fale-se, por exemplo, do Direito Penal, do Direito de Família, do Direito do Consumidor, do Direito Tributário (embora neste o avanço, no Brasil, tenha sido muito modesto, como se sabe), além de outros campos jurídicos. De toda maneira, o Direito do Trabalho (e também o Direito da Seguridade Social) consistem em campos jurídicos privilegiados para permitir o estudo e demonstrar a arquitetura principiológica humanista e social dessse novo constituicionalismo e, em harmonia a ela, da Constituição Brasileira de 1988.

2 Naturalmente que, no modelo britânico (revolução liberalista ainda no século XVII, como visto), o liberalismo, adaptado à condições nacionais específicas, não deu origem a um documento escrito concentrado de normas constitucionais, ao reverso do que iria alcançar nos EUA e, a partir da França, também na Europa continental.

3 A Conferência Internacional de Berlim, em 1890, reuniu dez Estados europeus, aprovando diversos direitos trabalhistas a serem incorporados em cada ordem jurídica nacional interna. A Encíclica Rerum Novarum, editada pelo Papa Leão XIII, em 1891, pregou a necessidade de uma postura mais compreensiva acerca da gravidade da questão social pelos setores dominantes (Estado e classes dirigentes), inclusive quanto ao sindicalismo, abrindo, assim, uma cunha na visão individualista excludente do liberalismo tradicional. Já a política previdenciária e trabalhista do Governo Bismarck, na Alemanha, inicia-se logo depois da unificação alemã (1871), criando regras legais e institutos de natureza previdenciária e trabalhista naquele país.

4 A superioridade da concepção constitucional principiológica sobre a antiga (positivismo tradicional) ou a renovada concepção positivista do Direito (neopositivismo) mostra-se ainda mais clara nas dramáticas conjunturas de emergência de experimentos autocráticos na sociedade política contemporânea - fases em que a fragilidade do positivismo ou do neopositivismo perante as autocracias torna-se manifesta, sem embargo da consistência, seriedade e independência de seus teóricos.

5 A cláusula implícita da reserva do possível transparece ainda em fundamentos congêneres, usualmente de caráter metajurídico, que assumem a força de um suposto pilar estrutural objetivo da vida real a informar a interpretação jurídica. Com isso, seu papel se alarga por além das restrições estatais à efetividade dos direitos fundamentais para abranger, também, lamentavelmente, as restrições do poder econômico privado aos direitos individuais e sociais que lhe são antepostos.

\section{REFERÊNCIAS}

ALEXY, Robert. Teoria de los derechos fundamentales. Tradución de Ernesto Garzón Valdés. Madrid: Centro de Estudios Constitucionales, 1993.

BARROSO, Luís Roberto. Fundamentos teóricos e filosóficos do novo Direito Constitucional brasileiro. Jus Navegandi, Teresina, ano 6, n. 59, out. 2002. Disponível em: https://jus.com.br/artigos/3208/fundamentos teoricos-efilosoficos-do-novo-direito-constitucional-brasileiro/2. Acesso em 17 de out. 2018. 
. 0 direito constitucional e a efetividade de suas normas: limites e possibilidades da Constituição brasileira. 9. ed. Rio de Janeiro: Renovar, 2009.

BONAVIDES, Paulo. Do estado liberal ao estado social. 7. ed. São Paulo: Malheiros, 2004.

Curso de direito constitucional. 15 ed. São Paulo: Malheiros, 2004 (também 10. ed., São Paulo: Malheiros, 2000).

CANOTILHO, J. J. Gomes. Direito constitucional e teoria da constituição. 7. ed. Coimbra: Almedina, 2003.

DELGADO, Gabriela Neves; BORGES, Lara Pereira de Faria. A revisitação do princípio da proteção pelo discurso constitucional trabalhista no Tribunal Superior do Trabalho. In: DELGADO, Gabriela Neves; PIMENTA, José Roberto Freire; MELLO FILHO, Luiz Philippe Vieira de; LOPES, Othon de Azevedo (Coords.). Direito constitucional do trabalho: princípios e jurisdição constitucional do TST. São Paulo: LTr, 2015, p. 40-42.

DELGADO, Mauricio Godinho, Constituição da República, Estado Democrático de Direito e Direito do Trabalho. In DELGADO, M. G.; DELGADO, G. N. Constituição da República e Direitos Fundamentais: dignidade da pessoa humana, justiça social e Direito do Trabalho. 3. ed. São Paulo: LTr, 2015, p. 31-54.

. DELGADO, Mauricio Godinho. Princípios Constitucionais do Trabalho e Princípios de Direito Individual e Coletivo do Trabalho. 5. ed. São Paulo: LTr, 2015.

DELGADO, Mauricio Godinho; DELGADO, Gabriela Neves. Constituição da República e Direitos Fundamentais: dignidade da pessoa humana, justiça social e Direito do Trabalho. 3. ed. São Paulo: LTr, 2015.

A Matriz da Constituição de 1988 como Parâmetro para a Análise da Reforma Trabalhista. Revista Magister de Direito do Trabalho. Ano XIV, no 0 , Set.-Out. de 2017, p. 27-44.

DWORKIN, Ronald. Los Derechos en Serio. Barcelona: Ariel, 1999. 
ESPINDOLA, Angela Araújo da Silveira; CUNHA, Guilherme Cardoso Antunes. 0 processo, os direitos fundamentais e a transição do Estado Liberal Clássico para o Estado Contemporâneo. Revista Ciências Sociais da Universidade Gama Filho. Rio de Janeiro: Editora Gama Filho, v.16, p. 45-63, 2010.

FERRAJOLI, Luigi; STRECK, Lenio Luiz; TRINDADE, André Karam (Orgs.). Garantismo, hermenêutica e (neo) constitucionalismo: um debate com Luigi Ferrajoli. Porto Alegre: Livraria do Advogado, 2012.

LORENZETTI. Ricardo Luís. Teoria da decisão judicial: fundamentos de direito. Tradução Bruno Miragem e Claudia Lima Marques. São Paulo: Revista dos Tribunais, 2009.

SARLET, Ingo Wolfgang. Dignidade da pessoa humana e direitos fundamentais: na Constituição Federal de 1988. Porto Alegre: Livraria do Advogado, 2002.

A eficácia dos direitos fundamentais. 4. ed. Porto Alegre: Livraria do Advogado, 2004.

SILVA, José Afonso da. Curso de direito constitucional positivo. 40. ed. São Paulo: Malheiros, 2017.

SILVA, Virgilio Afonso da. Direitos fundamentais: conteúdo essencial, restrições e eficácia. São Paulo: Malheiros, 2009.

STRECK, Lenio Luiz; MORAIS, José Luiz Boszan de. Ciência Política e Teoria do Estado. 8. ed. Porto Alegre: Livraria do Advogado, 2014.

VIEIRA JUNIOR, Dicesar Beches. Neoconstitucionalismo: definição, crítica e concretização dos direitos fundamentais. Revista Constituição e Garantia de Direitos, v. 6, n. 02, 15 set. 2014.

Recebido em: 31-3-2019

Autor convidado 


\section{Mauricio Godinho Delgado}

Professor Titular do Centro Universitário do Distrito Federal (UDF) e de seu Mestrado em Direito das Relações Sociais e Trabalhistas. Ministro do Tribunal Superior do Trabalho (TST). Doutor em Filosofia do Direito pela UFMG e Mestre em Ciência Política pela UFMG. Autor de livros e artigos em Direito Constitucional, Direito do Trabalho, Direito Constitucional do Trabalho, Direito Processual do Trabalho e Ciência Política. E-mail: gmmgd@tst,jus.br

\section{Rúbia Zanotelli de Alvarenga}

Professora Titular do Centro Universitário do Distrito Federal (UDF) e de seu Mestrado em Direito das Relações Sociais e Trabalhistas. Doutora em Direito pela PUC Minas e Mestre em Direito do Trabalho pela PUC Minas. Autora de livros e artigos em Direito do Trabalho, Direito Constitucional do Trabalho, Direitos Humanos e Direito Internacional do Trabalho. E-mail: rubiazanotelli@ terra.com.br

\section{Tâmara Matias Guimarães}

Mestranda em Direito das Relações Sociais e Trabalhistas pela UDF. Graduada em Direito pela Universidade Federal do Maranhão - UFMA; especialista em Direito do Trabalho e Processo do Trabalho. Advogada. Professora universitária na Unidade de Ensino Superior do Sul do Maranhão - UNISULMA em Imperatriz - MA. E-mail: tamara@matiasematias.com.br

Centro Universitário do Distrito Federal. Programa de Pós-graduação em Direito Setor de Edifícios Públicos Sul, Eq 704/904, Conj. A - Asa Sul, Brasília - DF, 70390-030 
